\title{
SOSIALISASI \\ PENYUSUNAN LAPORAN KEUANGAN AKUNTANSI BAGI USAHA KELOMPOK INDUSTRI RUMAH TANGGA KECAMATAN LANDASAN ULIN KOTA BANJARBARU
}

\author{
Heru Kartika Candra ${ }^{1}$,Emy Iryanie ${ }^{2}$, Heldalina ${ }^{3}$, Phaureula Artha W. $^{4}$ \\ Politeknik Negeri Banjarmasin ${ }^{1,2,3,4}$ \\ Hkc131170@gmail.com
}

\begin{abstract}
In the implementation of UKM empowerment, the Cooperative Service has a work program, one of which is to establish cooperation / work partners with outsiders as a support for the expertise in Information Technology-based expertise. One of the outside parties who can cooperate is Higher Education in this case Banjarmasin State Polytechnic. As a form of concern for community development, Banjarmasin State Polytechnic in this case represented by the Computerized Study Program as an educational institution feels the need to participate in providing thought, training and scientific application Accountingbased which is felt to be needed by an organization that has business references like UKMs.

The main problem is in the aspect of financial administration. Community Service Activities on Community Partnership Program for Mitra Kedai Unyui which will be implemented through the Capacity Building Program for human resource development in understanding and utilizing knowledge in the field of Accounting, so that it is expected that later every UKM member, especially Kedai Unyui UKM can not only understand accounting knowledge as a knowledge base financial administration but can design and make accounting reporting according to the needs of each UKM.

The materials that will be provided in training for UKM members include several strategies in constructing their identity. Jones (1990) states a summary of five strategies in the construction of self-presentation obtained from experiments on interpersonal situations: Ingratiation, Competence, Intimidation, Exemplification and Supplication. These materials are given based on the results of the needs analysis of UKM members.

The results achieved in this Community Service activity are an understanding of basic accounting theory in carrying out administrative processes that are right and on target in accordance with the fields carried out by the UMKM, namely the implementation and development of business enterprises. In addition the participants have been given training on how to make simple financial statements in accordance with the transactions that occur during business implementation.
\end{abstract}

Keywords: Accounting, Financial Statements, UKM 


\section{RINGKASAN}

Dalam pelaksanaan pemberdayaan UKM, Dinas Koperasi memiliki program kerja salah satunya yaitu menjalin kerjasama/mitra kerja dengan pihak luar sebagai support bidang keahlian yang berbasis Teknologi Informasi. Salah satu pihak luar yang dapat melakukan kerjasama yaitu Perguruan Tinggi dalam hal ini Politeknik Negeri Banjarmasin.Sebagai bentuk kepedulian terhadap pengembangan masyarakat, Politeknik Negeri Banjarmasin dalam hal ini diwakili oleh Program Studi Komputerisasi sebagai lembaga pendidikan merasa perlunya ikut serta memberikan pemikiran, pelatihan dan penerapan keilmuan yang berbasis Akuntansi yang dirasa diperlukan oleh sebuah organisasi yang beracuan bisnis seperti halnya UKM.

Permasalahan utama terdapat pada segi administrasi keuangan. Kegiatan Pengabdian kepada Masyarakat pada Program Kemitraan Masyarakat bagi Mitra Kedai Unyui yang akan dilaksanakan melalui Program Peningkatan Kemampuan pengembangan sumber daya manusia dalam memahami dan memanfaatkan pengetahuan dibidang Akuntansi, sehingga diharapkan nantinya setiap anggota UKM khususnya UKM Kedai Unyui tidak hanya bisa memahami pengetahuan akuntansi sebagai dasar pengetahuan administrasi keuangan namun dapat merancang dan membuat pelaporan akuntansi sesuai kebutuhan UKM masingmasing.

Materi-materi yang akan diberikan dalam pelatihan bagi anggota UKM meliputi beberapa strategi dalam mengkonstruksi identitas mereka. Jones (1990) menyatakan rangkuman dari lima strategi dalam konstruksi presentasi diri yang diperoleh dari eksperimen terhadap situasi interpersonal:Ingratiation, Competence, Intimidation, Exemplification dan Supplication. Materi-materi tersebut diberikan berdasarkan hasil analisis kebutuhan terhadap anggota UKM.

Hasil yang telah dicapai pada kegiatan Pengabdian Kepada Masyarakat ini yaitu pemahaman tentang teori akuntansi dasar dalam melaksanakan proses administrasi yang benar dan tepat sasaran sesuai dengann bidang yang dijalankan pihak UMKM yaitu pelaksanaan dan pengembangan usaha bisnis. Selain itu para peserta telah diberikan pelatihan bagaimana membuat laporan keuangan sederhana sesuai dengan transaksi yang terjadi pada saat pelaksanaan bisnis.

\section{Kata kunci : Akuntansi, Laporan Keuangan, UKM}

\section{PENDAHULUAN}

Pengabdian kepada masyarakat yang dilakukan pada saat ini mengambil obyek Usaha Micro Kecil Menengah yang berada di kota Banjarbaru Provinsi Kalimantan Selatan. Hal ini dikarenakan Dinas Koperasi dan Tenaga Kerja Kota Banjarbaru berupaya meningkatkan kinerja UMKN yang berada di bawah pengawasannya. Upaya ini ditandai dengan melakkukan pendataan UMKN dan berusaha memberikan pelayan berupa penyuluhan, pelatihan dan peningkatan status dari yang belum berbadan hukum menjadi memiliki surat pendirian usaha. Penjelasan di atas sangat erat hubungannya dengan kondisi banyaknya UKM yang 
ada di wilayah Kalimantan Selatan pada umumnya. Sejak dilaksanakannya sensus ekonomi 2016 yang berakhir 31 Mei 2016 lalu, terdata sebanyak 398.000 lebih tempat usaha di daerah ini. Mayoritas tempat usaha yang berhasil didata merupakan jenis Usaha Kecil Mikro dan Menengah (UKM), terutama kios atau warung kecil. (data BPS Kalsel, 2016)

UKM yang dikelola masih sebuah usaha Rumah Tangga dan untuk wilayah pemasarannya masih di sekitar tempat usaha dan sebagian di wilayah Kota Banjarbaru. Manajemen yang dikelola oleh pemilik UKM ini masih bersifat konvensional, dilihat dari pencatatan akuntansi keuangannya dan model pemasarannya, meskipun pemasarannya ada juga melalui media social facebook dan whatshap. Proses produksi yang dilakukan memerlukan pengaturan manajemen yang tepat agar mendapatkan prediksi pengembangan usaha yang terukur dan signifikan, sehingga mendapatkan gambaran yang jelas tentang perkembangan keuntungan yang diperoleh dari usaha yang dilakukan.

Dari penjelasan mitra UKM di atas, maka dapat disimpulkan bahwa permasalahan utama terdapat pada segi pengaturan administrasi keuangan dengan benar. Para pengelola usaha ini membutuhkan pelatihan dalam pengelolaan administrasi keuangan agar mengetahui dengan pasti perkembangan pendapatan mereka. Selain itu, mereka juga membutuhkan pelatihan teknik perancangan laporan keuangan sesuai dengan aturan akuntansi, dikarenakan kurangnya pengetahuan tentang akuntansi. Para pengelola juga membutuhkan pelatihan tentang manajemen pemasaran dan manajemen keuangan berbas teknologi informasi.

\section{METODE KEGIATAN / SOLUSI / TEKNOLOGI}

Pada kegiatan kepada masyarakat yang dilaksanakan bekerjasama dengan UKM Kedai Unyui, metode yang dipakai adalah Pendidikan Masyarakat, dimana secara menyeluruh dapat digambarkan sebagai berikut :

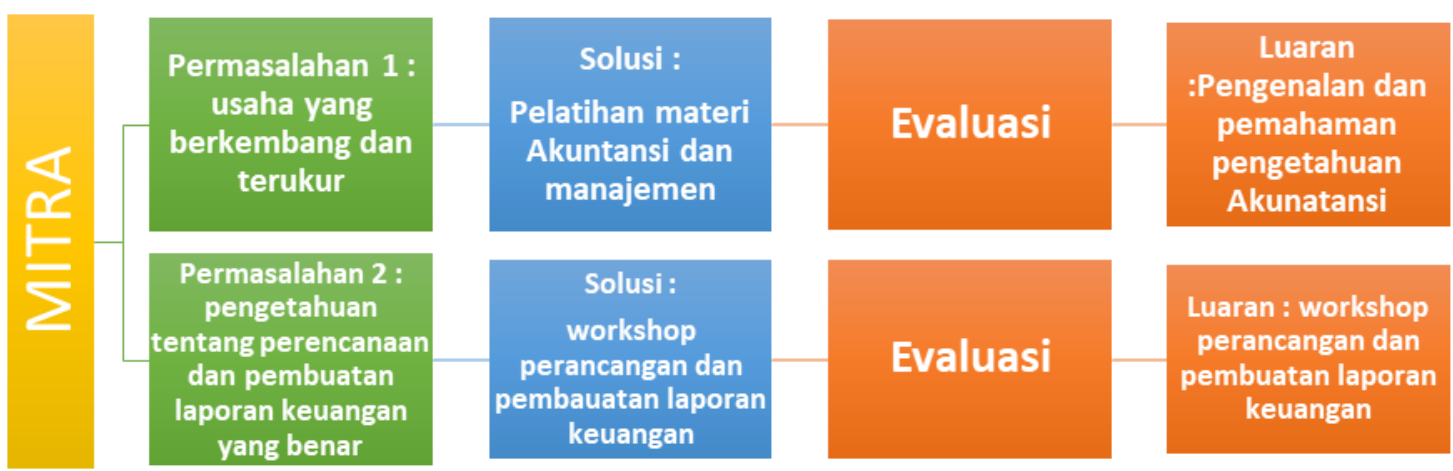

Gambar 1. Tahapan pelaksanaan kegiatan

\section{Tahapan Kegiatan}

Tahapan kegiatan pelatihan perancangan dan pembuatan laporan keuangan untuk anggota UKM ini meliputi:

1. Tahap Persiapan, meliputi: 
a. Pada tahap persiapan pertama ini dilakukan analisis kebutuhan (needs survey) permasalahan yang dihadapi masyarakat sasaran dan merumuskan masalah sehingga dapat dicari solusi pemecahan. Hasil kegiatan analisis kebutuhan ini menunjukkan bahwa:

- Kemampuan memahami materi akuntansi sangat dibutuhkan anggota UKM untuk mendukung usaha mereka.

- Sebagian besar anggota UKM belum menguasai pengolahan laporan keuangan yang dapat mendukung profesi mereka.

b. Pada tahap persiapan kedua ini dilakukan persiapan materi pelatihan pengolahan laporan keuangan UMKM dengan menyusun modul yang akan digunakan dalam pelatihan.

c. Pada tahap persiapan ketiga dilakukan rekruitmen peserta pelatihan, dengan memberikan penawaran kepada anggota UKM untuk bersedia mengikuti pelatihan ini. Jumlah peserta pelatihan berjumlah 18 peserta meliputi anggota UKM mitra (Hipmikindo cabang Banjarbaru).

d. Pada tahap persiapan keempat dilakukan penentuan waktu pelatihan dengan meminta pertimbangan dari peserta pelatihan.

e. Pada tahap persiapan kelima dilakukan pengadaan alat tulis peserta sebagai penunjang kegiatan pelatihan.

2. Tahap Pelaksanaan Setelah semua tahap-tahap persiapan dilaksanakan, maka akan segera dilaksanakan pelatihan.. Pelatihan ini akan dilaksanakan selama 2 hari dengan jadwal pertemuan 6 jam sehari. Pertemuan akan dimulai pada minggu pertama Agustus 2018. Peserta pelatihan direncanakan berjumlah 10 peserta dan akan dibagi dalam dua kelompok dengan tujuan untuk mengoptimalkan keberhasilan pelatihan.

Rancangan pelaksanaan pelatihan adalah sebagai berikut:.

Tabel 1. Rancangan Kegiatan Sosialisasi dan Pelatihan Pengolahan Laporan Keuangan

\begin{tabular}{|c|l|c|}
\hline Pertemuan (hari) & \multicolumn{1}{|c|}{ Topik } & Alokasi Waktu (jam) \\
\hline 1 & $\begin{array}{l}\text { Pengenalan materi Akuntansi } \\
\text { UMKM }\end{array}$ & 6 \\
\hline 2 & $\begin{array}{l}\text { Latihan Perancangan dan } \\
\text { Pembauatan Laporan Keuangan }\end{array}$ & 6 \\
\hline
\end{tabular}

\section{HASIL DAN PEMBAHASAN}

\section{Hasil Pelaksanaan Kegiatan}

\section{A. Hasil Pelaksanaan Kegiatan}

Kegiatan sosialisasi pembuatan laporan keuangan berbasis akuntansi bagi anggota UKM dapat menghasilkan jiwa terampil peserta dibidang Akuntansi, melalui pelatihan dan Sosialisasi Penyusunan Laporan Keuangan Akuntansi Bagi Usaha Kelompok Industri Rumah Tangga Kecamatan Landasan Ulin 
Kota Banjarbaru yang dilaksanakan pada tanggal 6 Oktober 2018. Kegiatan pelatihan berjalan dengan lancar dihadiri oleh 18 peserta.

Peserta pelatihan terlihat antusias dengan materi pelatihan yang diberikan. Hal ini terlihat dari awal hingga akhir acara, semua peserta mengikuti dengan baik. Materi mengenai teori pembuatan laporan keuangan berbasis Akuntansi, diberikan pada sesi pertama pelatihan. Pada sesi kedua peserta pelatihan melakukan workshop untuk latihan pembuatan laporan akuntansi. Peserta pelatihan melakukan analisa data, perhitungan manual dan dilanjutkan dengan pembuatan laporan keuangan dengan media yang telah disediakan.

Berdasarkan hasil kegiatan dapat diidentifikasi mengenai tingkat pemahaman peserta pengabdian adalah bahwa $90 \%$ peserta pelatihan memahami teori dan implementasi pembuatan laporan keuangan, mulai dari tahap persiapan data sampai pembuatan laporan akhir. Hasil yang terkumpul adalah sebanyak 18 laporan keuangan meskipun ada yang masih salah.

\section{B. Pembahasan}

Kegiatan Sosialisasi Penyusunan Laporan Keuangan Akuntansi Bagi Usaha Kelompok Industri Rumah Tangga Kecamatan Landasan Ulin Kota Banjarbaru yang bertujuan untuk meningkatkan profesionalitas pelaku bisnis, dapat berjalan dengan lancar. Sosialisasi pengetahuan dan proses Penyusunan Laporan Keuangan Akuntansi Bagi Usaha Kelompok Industri Rumah Tangga memang nyata-nyata dibutuhkan bagi pelaku bisnis micro pada UKM. Kebanyakan peserta mengeluhkan kurangnya pengetahuan dan pemahaman akan proses pembuatan laporan keuangan berbasis Akuntansi yang benar, untuk meningkatkan profesionalitas mereka sebagai anggota organisasi UKM maupun sebagai individu pelaku bisnis. Untuk itu diperlukan praktek nyata yang dapat meningkatkan kualitas diri pelaku bisnis dan keterampilan dengan menerapkan pengetahuan dibidang Akuntansi. Hasil pembelajaran tidak akan banyak bermanfaat bagi orang lain kecuali dapat diterapkan pada kondisi nyata.

Oleh karena itu pelaku bisnis merasakan banyak manfaat yang diperoleh dari pelatihan ini untuk meningkatkan kemampuannya dalam menerapkan ilmu terampil dan dapat dimanfaatkan pada kegiatan-kegiatan nyata, dalam hal ini pelaku bisnis hendaknya juga bertanggungjawab atas pengembangan ilmunya. Agar ilmu yang diembannya dapat dikembangkan dan tidak tertinggal pelaku bisnis seyogyanya melakukan kajian keilmuan yang menjadi bidangnya, dalam hal ini bidang akuntansi. Hal ini akan berdampak pada peningkatan penguasaan pengetahuan dan keterampilannya sebagai seorang profesional.

\section{Faktor Pendukung Kegiatan}

Kegiatan pelatihan ini dapat berjalan dengan lancar. Hal ini disebabkan adanya faktor yang mendukung berjalannya kegitan pengabdian. Hal-hal yang mendukung berjalannya kegiatan pengabdian ini dapat diidentifikasi diantaranya antusisme para peserta pelatihan.

Faktor yang mendukung kegiatan adalah antusiasme peserta untuk memahami materi Akuntansi dari segi teori dan penerapannya untuk membantu 
mempermudah dalam kegiatan pembuatan laporan keuangan. Antusisme dibuktikan dengan banyaknya pertanyaan yang muncul ketika pelaksanaan diskusi kelompok, pengerjaan tugas yaitu penyelasaian kasus akuntansi dalam pembuatan pelaporan keuangan berbasis Akuntansi.

\section{Faktor Penghambat Kegiatan}

Lancarnya pelaksanaan kegiatan pengabdian bukan berari tanpa hambatan. Selama pengabdian ada beberapa hal yang diidentifikasi sebagai factor penghambat kegiatan pengabdian diantaranya adalah rendahnya pengetahuan tentang Akuntansi khususnya dalam pembuatan pelaporan bagi sebagian peserta pelatihan.

Faktor yang menghambat jalannya pengabdian yaitu bahwa kemampuan penguasaan Akuntansi tidak hanya membutuhkan kemampuan akan tetapi juga membutuhkan kemauan. Banyak peserta yang mempunyai kemampuan untuk mengenal Akuntansi akan tetapi belum mempunyai kemauan untuk belajar lebih luas tentang Akuntansi khususnya pembuatan laporan keuangan berbasis Akuntansi. Hal ini disebabkan kurangnya pemahaman mengenai materi-materi Akuntansi.

\section{Luaran Yang Dicapai}

Luaran yang dicapai yaitu Penyusunan laporan keuangan bagi industri rumah tangga dan publikasi kegiatan pada jurnal pengabdian kepada masyarakat yaitu Jurnal Pengabdian Kepada Masyarakat “Jurnal IMPACT” Poliban.

\section{KESIMPULAN}

Hampir semua peserta antusias dan merasakan manfaat pelatihan.

Pelaksanaan pengabdian untuk pengusaha micro UKM dapat disimpulkan berhasil sampai tahap pelatihan penyelesaian kasus akuntansi dengan membuat laporan keuangan. Keberhasilan ini ditunjukkan antara lain oleh :

a. Adanya kesesuaian materi dengan kebutuhan pengusaha micro UKM untuk meningkatkan profesionalitasnya.

b. Adanya respon yang positif dari peserta mengingat kegiatan pengabdian merupakan kebutuhan pengusaha dalam rangka peningkatan profesionalitasnya.

Sebagian besar (90\%) peserta telah memahami teori dan implementasi penyususnan lapporan keuangan berbasis Akuntansi, mulai dari tahap persiapan data sampai pembuatan laporan akhir. Hasil yang terkumpul adalah sebanyak 18 laporan keuangan meskipun ada yang masih salah.

\section{UCAPAN TERIMA KASIH}

Dengan terlaksanananya kegiatan pengabdian kepada masyarakat, maka tim pengabdian kepada masyarakat prodi D3 Komputerisasi Akuntansi Jurusan Akuntansi Politeknik Negeri Banjarmasin, mengucapkan banyak terima kasih atas dukungan yang diberikan sehingga kegiatan ini dapat terlaksana dengan baik dan lancar. Ucapan terima kasih ini kami sampaikan kepada :

1. Direktur POLIBAN

2. Ketua P3M POLIBAN 
3. Ketua Jurusan Akuntansi

4. Ibu Nurachmi Deasy Iriany sebagai pelilik UKM Kedai Unyui

5. Ketua HIPMIKINDO cabang Banjarbaru

6. Rekan-rekan 1 (satu) Tim Pengabdian

\section{DAFTAR PUSTAKA}

Dirjen Dikti. 2005. Pedoman Umum: Pengembangan Sistem Asesmen Berbasis Kompetensi. Depdiknas: Jakarta.

Gagne, R. M. 1985. The conditions of learning and theory of instruction. New York: CBS College Publishing.

Gall, M. D., Gall, J. P., \& Borg, W. R. 2003. Educational research: An introduction. Seventh Edition. Boston: Pearson Education, Inc.

Heinich, R., Molenda, M., Rusell, J. D., \& Smaldino, S.E. 2002. Instructinal media andtechnology for learning, 7th edition. New Jersey: Prentice Hall, Inc.

Januszewski, A., Molenda, M. 2008. Educational Technology. New York: Lawrence Erlbaum Associates.

Martha, E. R. D., Rosalind, H. \& Ted, W. P. 1993. Theory and Research in Social Education. Vol. 4. Washington DC: NCSS.

Reigeluth, C. M. 1999. Instructioanl-design theories and models: A new paradigm ofinstructional theory. Volume II. New Jersey: Lawrence Erlbaum Associates,Publishers.

Reigeluth, C. M. 1983. Instructioanl-design theories and models: An overview of their currentstatus. Volume I. New Jersey: Lawrence Erlbaum Associates, Publishers.

Slavin, R. E. 2006. Educational Psychology, Theory and Practice. 6th. USA: A pearson education company.

Smaldino, S.E. , Lowther, D.L. \& Russell, J.D. 2008. Instructional Media and

Technology forLearning. 9th Edition. Upper Saddle Rive NJ: Pearson Education, Inc. 